\title{
Comparative Study of Jute, E-glass and Carbon Kevlar Fabric Reinforced Polypropylene Composite
}

\author{
Md. Reazuddin Repon ${ }^{1,2, *}$, Md. Shariful Islam ${ }^{1}$, S. M. Mehedi Hasan ${ }^{1}$, Rajib Al Mamun ${ }^{1}$, Ruhul Amin Khan ${ }^{3}$ \\ ${ }^{1}$ Department of Textile Engineering, Khwaja Yunus Ali University, Bangladesh \\ ${ }^{2}$ Department of Production Engineering, Faculty of Mechanical Engineering and Design, Kaunas University of Technology, Lithuania \\ ${ }^{3}$ Institute of Radiation and Polymer Technology, Bangladesh Atomic Energy Commission, Bangladesh
}

Copyright $\odot 2019$ by authors, all rights reserved. Authors agree that this article remains permanently open access under the terms of the Creative Commons Attribution License 4.0 International License

\begin{abstract}
In this experiment, three types of fabric such as jute, E-glass and carbon Kevlar were selected to manufacture composites taking polypropylene (PP) as matrix material. The objective of this study is to compare the examined properties such as tensile modulus (TM), elongation at break percentage (EB \%), E-Modulus (EM) of jute, E-glass and carbon Kevlar fabric reinforced polypropylene composite. The properties of manufactured composite were evaluated experimentally using computerized UTM machine according to ASTM standards. Fourier transform infrared spectroscopy was used to identify the surface groups of the composites. Water absorption and fire retardant behavior of the composites were also performed. The results revealed that the tensile strength, E-Modulus and water absorption of carbon Kevlar composite were exhibited higher than the jute and E-glass fabric reinforced composites. Different scenario has observed for elongation percentage at break. The capacity of fire retardant was noticed higher in jute fabric composite than E-glass and carbon Kevlar.
\end{abstract}

Keywords Composite, Tensile Properties, Water Absorption, Jute Fabric, E-glass Fabric, Carbon Kevlar Fabric, Polypropylene (PP), Fire Retardant

\section{Introduction}

Nowadays, composites materials are broadly used in different diversified applications area because of their excellent and unique combination of physical and mechanical properties $[1,2]$. Composites are extensively used in the civil constructions, chemical equipment and machinery constructions, electrical and electronic equipment, automobile and marine industries, aircraft manufacturing and many more $[1,3-6]$. A lot of research works have been done on fibre reinforced composites with the synthetic matrix and synthetic reinforcements like glass, carbon, nylon and Kevlar fibres. Synthetic fibre reinforced thermoplastic composites are dominating over natural fibre reinforced composites due to their improved strength, stability, corrosion and moisture resistance properties [7-10].

Natural fibres have several advantages; for example, they have its low cost, low density, stiffness, high specific strength and modulus, recyclable, biodegradable, no health risk, easy and safe handling, light weight, easy availability, renewability, non-abrasiveness, easy processing, non-toxicity, high flexibility, acoustic insulation and much lower energy requirement for processing [11-17]. Among all the natural fibres, jute has comparatively better properties and appealed worldwide attention as a potential reinforcement of polymer composite because of its inherent properties such as high tensile strength, low density, inexpensive and abundantly available in tropical countries [1, 18-20].

Many researchers have investigated the various mechanical, thermal and physical properties of jute fibre reinforced composites. Different matrix materials were used in different research such as polyester resin, natural rubber, polypropylene, polyethylene, polycarbonate, epoxy resin, phenol formaldehyde etc [10, 21-28].

Glass fibers are used as a reinforcing agent for many polymer products; to form a very strong and relatively lightweight fiber-reinforced polymer (FRP) composite material called glass-reinforced plastic and most common types of used glass fibre is E-glass [29-33]. Many researchers explored many article regarding matrix comprised and properties of composites [34-39]. The wide application area including electronics, home and furniture, aviation and aerospace, boats and marine, medical, automobiles etc. of glass fibre reinforced composites has also discussed elaborately [29].

Kevlar fibre, due to its unique properties has become very popular as reinforcement in composite materials and its application has growth considerably. It is mainly popular for its increasing applications in industrial and 
advanced technologies like ballistic armor, helicopter blades, pneumatic reinforcement, sporting goods, etc. Compared to other synthetic fibers, it possesses significantly lower fiber elongation and higher tensile strength and modulus. Many researchers have been conducted characterization of Kevlar fibre and its composites in recent years [40-43].

The objective of this research work is to study the mechanical properties of jute, E-glass and carbon Kevlar fabric by incorporating them into polypropylene matrix to prepare the composites. Another goal of this investigation was to compare the properties between natural and synthetic fabric reinforced polypropylene composites. The composites were tested to evaluate the tensile properties such as tensile modulus, elongation percentage, and E-Modulus. Water absorption percentages and fire retardant property were also investigated.

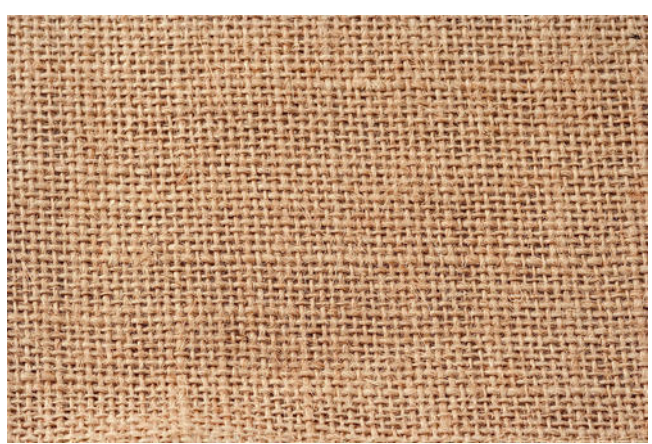

Figure 1. Jute fabric

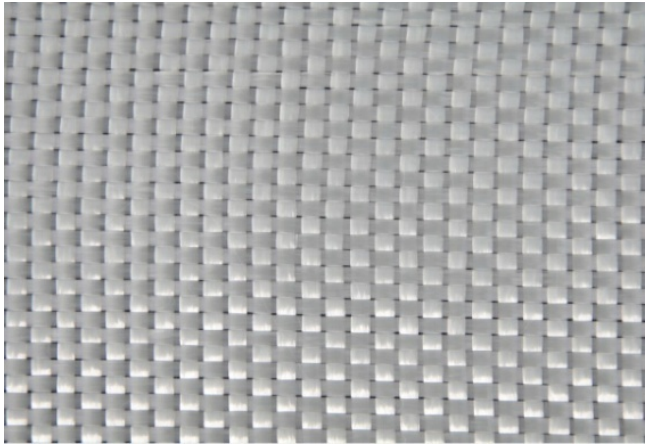

Figure 2. E-glass fabric

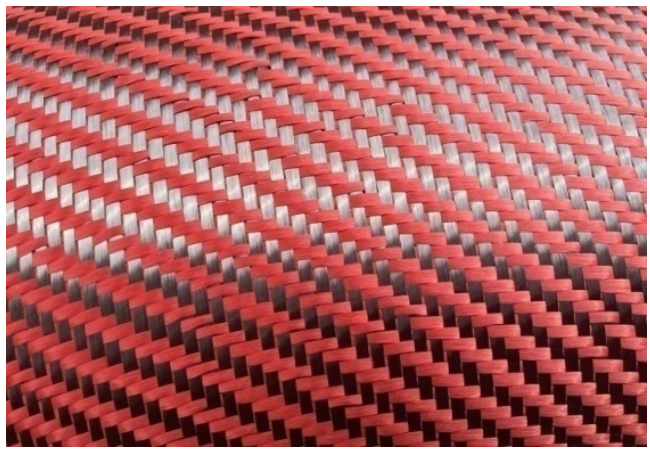

Figure 3. Carbon Kevlar fabric

\section{Materials and Methods}

\subsection{Materials}

\subsubsection{Matrix}

Polypropylene (PP) was used as matrix material in this experiment. Polypropylene (trade name: Cosmoplene) was purchased from Polyolefin Company Private Ltd., Singapore.

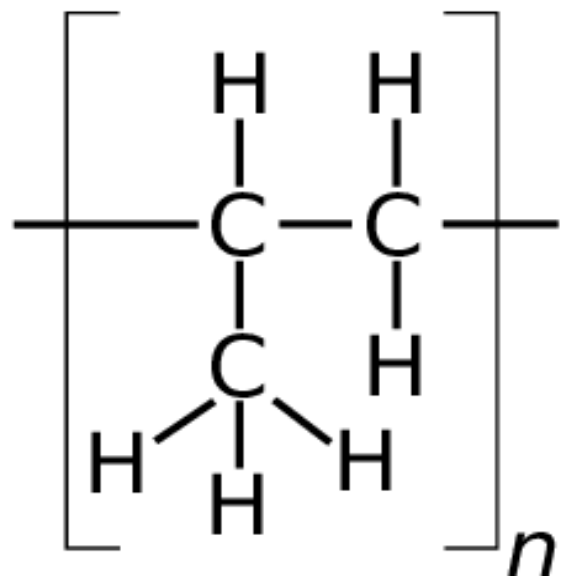

Figure 4. Molecular structure of poly-propylene (PP) [44]

\subsubsection{Reinforcements}

Three types of fabric such as jute, E-glass and carbon Kevlar were selected as the reinforcement in this study. Jute fabrics having plain weave structure were collected from Jute Research Institute, Dhaka, Bangladesh. E-glass fabric of plain weave structure and carbon Kevlar fabric of twill weave structure were purchased from Nasim Plastic Industries Limited, Dhaka, Bangladesh. Figure 1, 2 and 3 show the images of fabrics used in this experiment. The ends per inch (EPI), picks per inch (PPI) and areal density (GSM) of the jute, E-glass and carbon Kevlar fabrics are mentioned in the figure 5, 6 and 7 respectively.

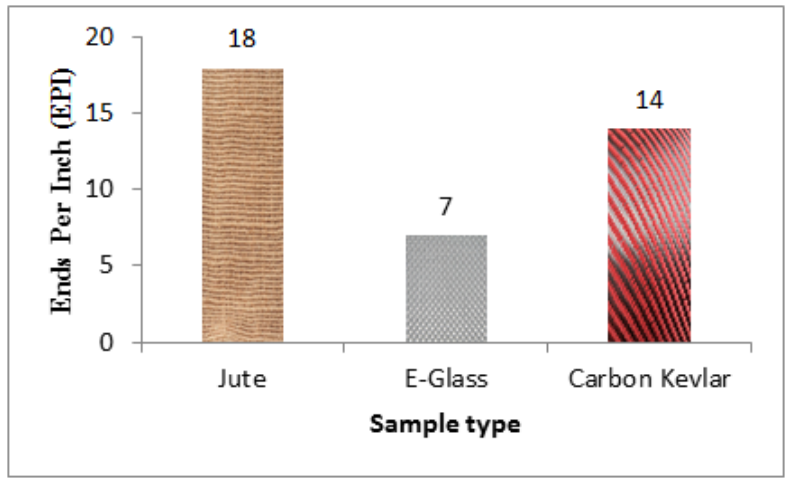

Figure 5. EPI of jute, E-glass and carbon Kevlar fabric 


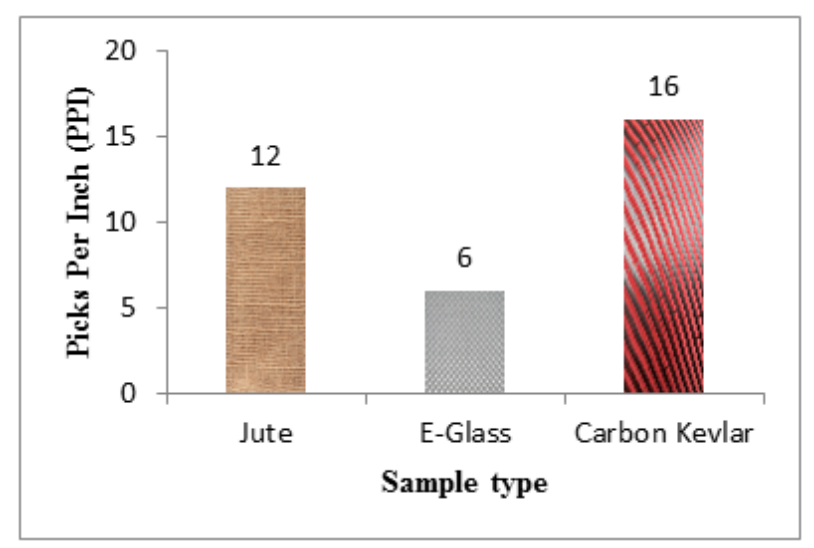

Figure 6. PPI of jute, E-glass and carbon Kevlar fabric

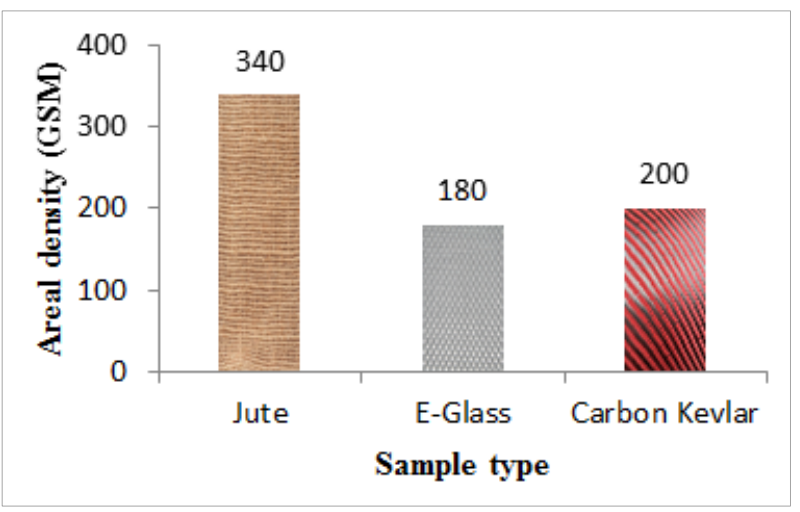

Figure 7. Areal density of jute, E-glass and carbon Kevlar fabric

\subsection{Methods}

\subsubsection{Sampling}

Different samples are identified as mentioned table 1.

Table 1. Sample Identification

\begin{tabular}{|c|c|}
\hline Sample types & Identification \\
\hline Jute fabric composite & JC \\
\hline E-Glass fabric composite & GC \\
\hline Carbon Kevlar fabric composite & CKC \\
\hline
\end{tabular}

\subsubsection{Fabrication of Composites}

Firstly, Polypropylene sheets were made from granules by placing them in between two steel plates in a heat compression molding machine maintaining the temperature 220 degree and pressure 5 ton for 10 minutes. The model of the machine was 3856, Carver Incorporation, USA. Cooling was done another compression molding machine of the same model for 5-7 $\mathrm{min}$ at room temperature using 5 metric ton pressure. The resultant polypropylene sheets were cut to the desired size $(12 \mathrm{~cm} \times$ $12 \mathrm{~cm}$ ) for composite manufacturing. Then, Jute, E-glass and Carbon Kevlar fabric reinforced composites were prepared by using polypropylene sheet in both sides. Here, the temperature and pressure were kept as 220 degree and 8 ton respectively for 10 minutes. The silicon paper was used for making both polypropylene sheet and composites. Testing specimens were prepared from the composite sheet by cutting with grinding machine carefully. Here, matrix to reinforcement ratio was maintained as $80: 20$ for preparing all composite samples.

\subsubsection{Testing of Samples}

\subsubsection{Determination of Tensile Strength, Elongation at Break and E-modulus}

The tensile properties such as tensile strength (TS), elongation at break percentage (EB\%) and E- modulus (Y) of the prepared composites were evaluated by a universal testing machine (UTM) (Model: H50KS-0404, HOUNSFIELD, series S, UK) at Institute of Radiation and Polymer Technology Laboratory, Bangladesh Atomic Energy Commission, Dhaka, Bangladesh. The specimens were prepared according to ASTM D638 standard. Crosshead speed of $10 \mathrm{~mm} / \mathrm{min}$ and a gauge length $20 \mathrm{~mm}$ were maintained during testing. Equation 1, 2 and 3 were used for measuring the tensile strength, elongation at break percentage and young's modulus respectively [28, 45]. Prior to testing all the testing specimens were conditioned at $25^{\circ} \mathrm{C}$ and $50 \%$ R.H for two days. All the mechanical properties of composites were tested under the similar conditions. The average value of five samples was taken as the final value of all tests.

$$
\text { Tensile strength, }(\mathrm{TS})=\frac{\mathrm{Fmax}}{\mathrm{A}}
$$

Where, $F_{\max }=$ Maximum load applied to the sample and $\mathrm{A}=$ Cross-sectional area of the sample.

Percentage of elongation-at-break was obtained by the following relation:

$$
\operatorname{EB}(\%)=\left(\frac{\Delta L_{b}}{L_{0}}\right) \times 100
$$

Where, $\Delta \mathrm{L}_{\mathrm{b}}=$ Extension at break point and $\mathrm{L}_{0}=$ Original length of the sample.

$$
\text { E-modulus, }(\mathrm{Y})=\frac{\mathrm{d} \sigma}{\mathrm{d} \varepsilon}
$$

Where, $\mathrm{d} \sigma=$ Stress at yield point and $\mathrm{d} \varepsilon=$ Strain at yield point

\subsubsection{Water Absorption}

Water absorption ability of composite samples was carried out in de-ionized water. The experiment was done at room temperature $\left(25^{\circ} \mathrm{C}\right)$ into a glass beaker containing $100 \mathrm{ml}$ water. The size of the specimens was $20 \mathrm{~mm} \times 10$ $\mathrm{mm} \times 2 \mathrm{~mm}$. The samples were dried in an oven at $105^{\circ} \mathrm{C}$ for $24 \mathrm{hr}$. before dipping. Then cooling was done in desiccators and immediately weighed. Then, composite samples were immersed in a static water bath at $25{ }^{\circ} \mathrm{C}$ for time interval of 1 hour (up to 4 hours). After certain periods of time, samples were taken out from the bath and wiped by tissue paper, then weighed. Water uptake percentage was 
calculated by using the equation 4 [45].

$$
\text { Water absorption }(\%)=\left[\frac{W_{f}-W_{i}}{W_{f}}\right] \times 100
$$

Where, $\mathrm{W}_{\mathrm{i}}=$ Initial weight (oven dry weight) and $\mathrm{W}_{f}=$ Final weight (after immerse in water).

\subsubsection{FTIR-ATR Spectroscopy Analysis}

In order to investigate the possible changes in the chemical composition of the composites, FTIR-ATR analysis was done on the Perkin Elmer SPECTRUM BX in the range of $4000-400 / \mathrm{cm}$.

\subsubsection{Flammability Testing}

Flammability test methods measure how easily materials ignite, how quickly they burn and how they react when burned. The materials are placed over a Bunsen burner horizontally and then calculate the rate at which the specimen burns.

\section{Results and Discussion}

\subsection{Tensile Properties}

\subsubsection{Tensile Strength}

Figure 8 depicts the tensile strength of jute, E-glass and carbon Kevlar fabric reinforced polypropylene composite. Concerning the tensile strength, the samples orders were found as $\mathrm{JC}<\mathrm{GC}<\mathrm{CKC}$. It is clearly evident from the figure 8 that the tensile strength of the samples $\mathrm{GC}$ and $\mathrm{CKC}$ were $74.61 \%$ and $200.16 \%$ higher respectively than the sample JC. The figure 8 also confirms that the tensile strength of carbon Kevlar fabric composite is higher than E-glass fabric composite.

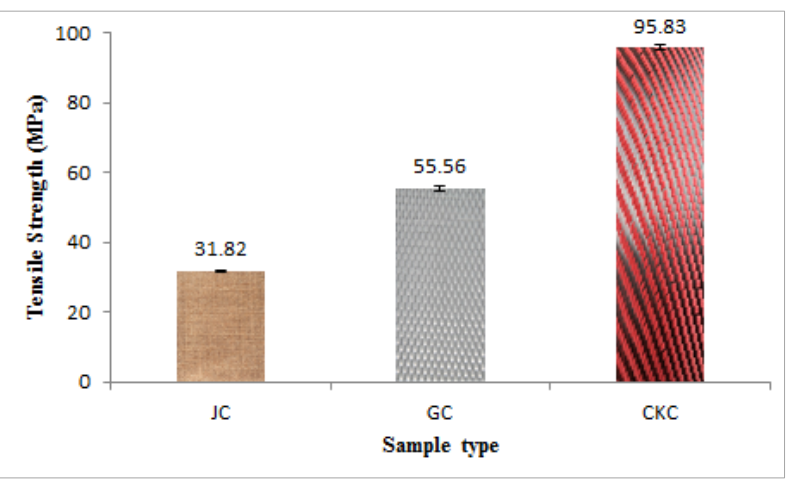

Figure 8. Tensile strength of Jute, E-glass and Carbon Kevlar fabric reinforced polypropylene composite

\subsubsection{Elongation at Break}

The elongation percentages at break of jute, E-glass and carbon Kevlar fabric reinforced polypropylene composite specimens are presented in figure 9. Regarding elongation $\%$, the samples orders were found as $\mathrm{CKC}<\mathrm{JC}<\mathrm{GC}$. It is observed from the figure 9 that the percentages of elongation at break of the sample GC is $12.65 \%$ higher and $0.98 \%$ lower for the sample CKC than JC.

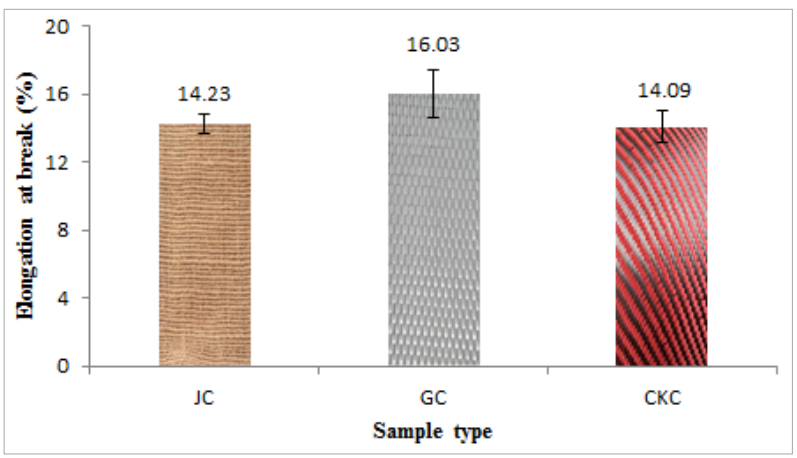

Figure 9. Elongation\% of Jute, E-glass and Carbon Kevlar fabric reinforced polypropylene composite

\subsubsection{E-Modulus}

Figure 10 illustrates the E-Modulus of jute, E-glass and carbon Kevlar fabric reinforced polypropylene composite. The samples orders were found as $\mathrm{GC}<\mathrm{JC}<\mathrm{CKC}$ depending on E-Modulus. The E-Modulus of the sample GC is $20.14 \%$ lower and $128.34 \%$ higher for the sample CKC than JC.

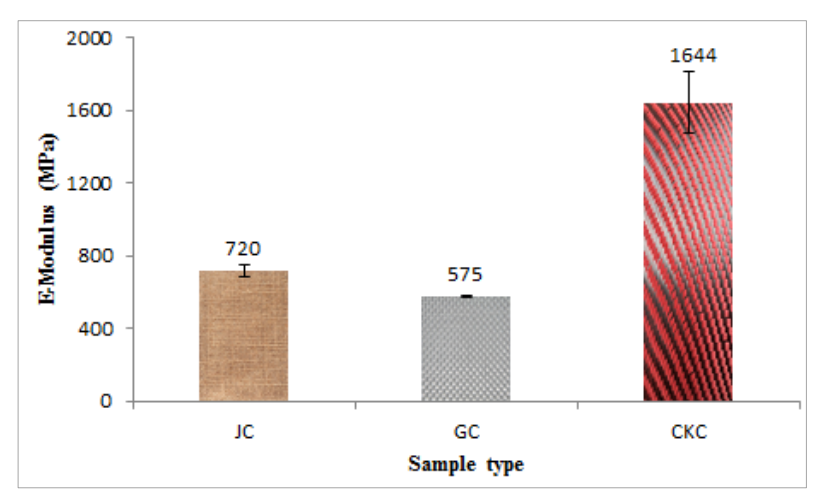

Figure 10. E-modulus of Jute, E-glass and Carbon Kevlar fabric reinforced polypropylene composite

\subsection{Water Absorption}

Water absorption test is very important for determining degradability of the material in moist condition. The water absorption percentages of jute, E-glass and carbon Kevlar fabric reinforced polypropylene composite specimens are shown in figure 11 for different soaking time. The water absorption percentages were increased with the increasing soaking time. The samples of carbon Kevlar fabric composite were exhibited higher water absorption than jute and E-glass composite. The maximum water absorption $(7.35 \%)$ was observed for the sample CKC at 4 hours soaking time. 


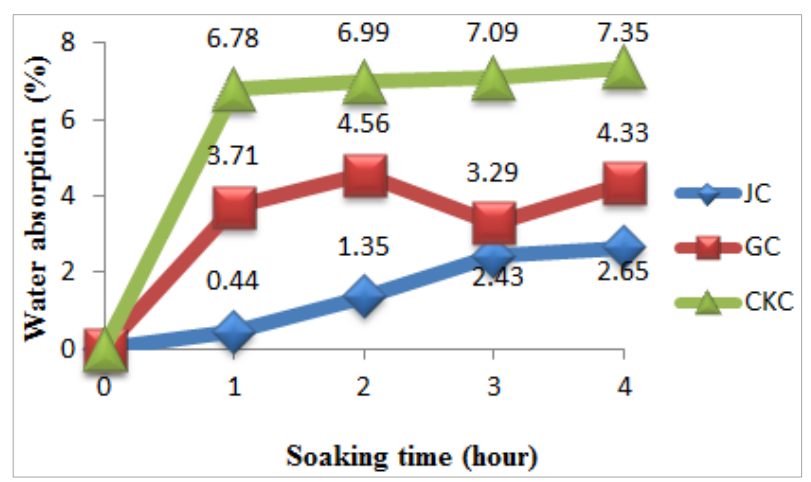

Figure 11. Water absorption of Jute, E-glass and Carbon Kevlar fabric reinforced polypropylene composite

\subsection{Fire Retardant Property}

Figure 12 illustrates the fire retardant property of jute, E-glass and carbon Kevlar fabric reinforced polypropylene composite. The samples orders were found as JC $>$ GC $>$ CKC depending on firing time and $\mathrm{GC}<\mathrm{CKC}<\mathrm{JC}$ were found depending on burning time. The firing time of the samples GC and CKC were observed $46.15 \%$ and $53.85 \%$ lower respectively than JC. Accordingly, the burning time was detected as 50.55\% lower for the sample GC and 39.84\% fabric reinforced polypropylene composites. lower for the sample CKC compared to JC.

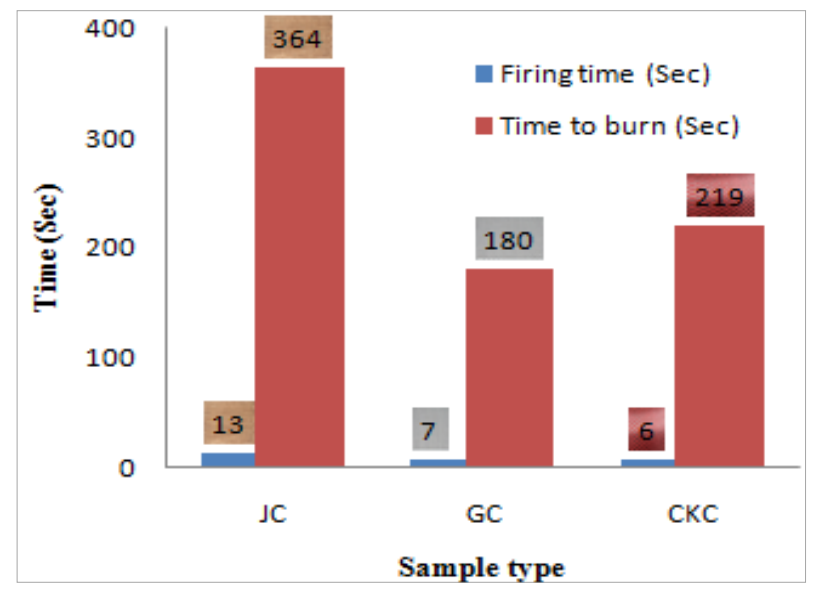

Figure 12. Fire retardant of Jute, E-glass and Carbon Kevlar fabric reinforced polypropylene composite

\subsection{FTIR-ATR Analysis}

To examine the presence and the type of interfacial bond in the composites, FTIR experiments were performed at the range from 4000 to $400 \mathrm{~cm}^{-1}$. Figure 13 represents the FTIR-ATR spectra of jute, E-glass and carbon Kevlar

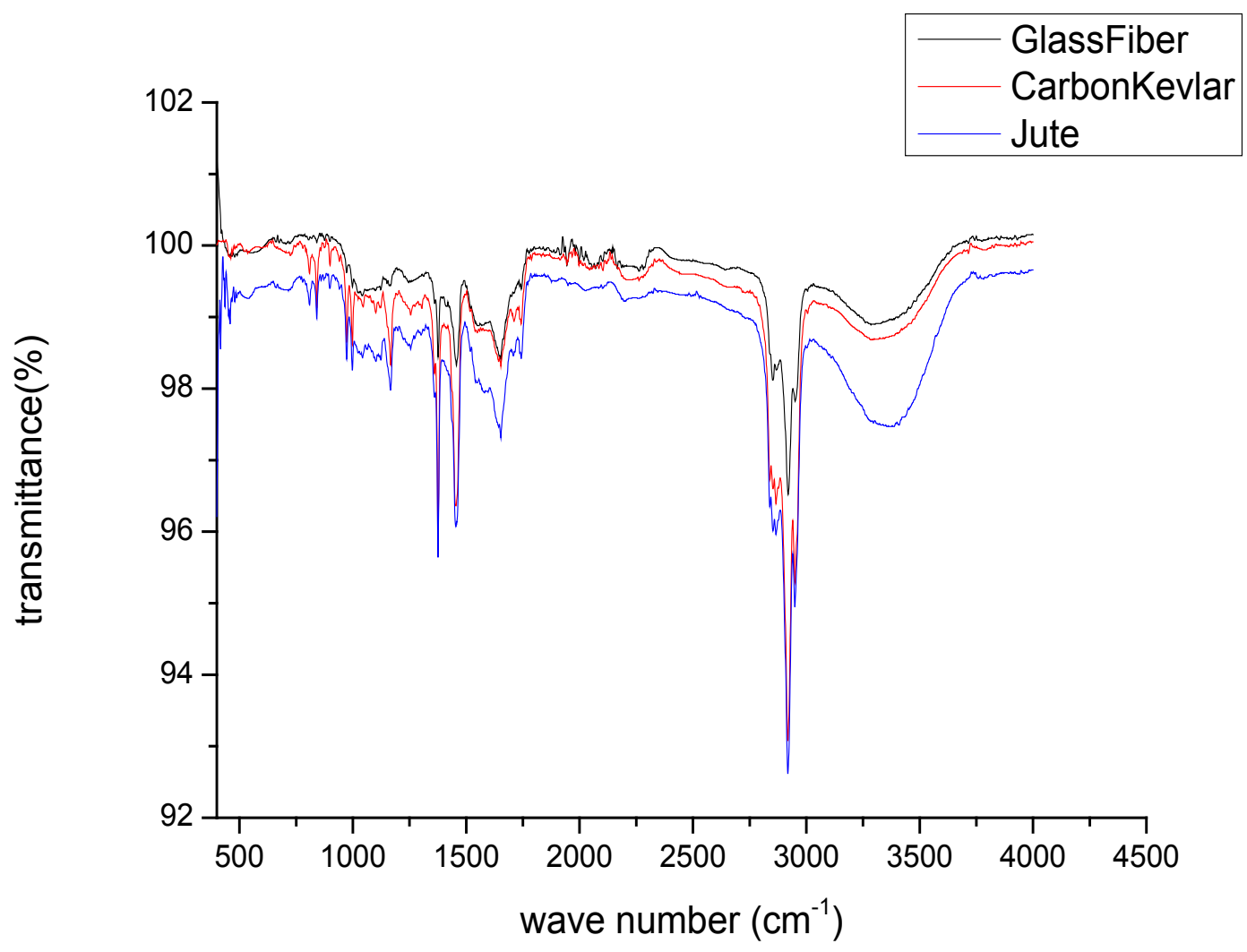

Figure 13. FTIR-ATR spectra of jute, E-glass and carbon Kevlar fabric reinforced polypropylene composite 
3200-3550 strong and broad peaks indicate O-H stretching bond for alcohol which is intermolecular bonded and $2500-3000 \mathrm{~cm}^{-1}$ adsorption could be by alkane $\mathrm{C}-\mathrm{H}$ bond, aryl or vinyl $\mathrm{C}-\mathrm{H}$ bond, aldehyde $\mathrm{C}-\mathrm{H}$ or carboxylic acid $\mathrm{C}-\mathrm{H}$ bond. All alkane, alkene and alkyne $\mathrm{C}-\mathrm{H}$ bonds have many tiny peaks. Alkene have very sharp peak around at $3300 \mathrm{~cm}-1$. Evidence of the presence of an aldehyde can be found around $2700-2900 \mathrm{~cm}^{-1}$ mark (doublet peak). And, carboxylic acid O-H bond appears as a wide, broad peak in the spectrum. Therefore, near $2900 \mathrm{~cm}-1$ peak is neither for $\mathrm{sp} 2$, sp hybridization nor aldehyde and carboxylic acid. Since, 2840-3000 cm-1 peak is due to alkane, therefore adsorption peak near $2900 \mathrm{~cm}-1$ is responsible for alkane. Peak on 1465 is due to $\mathrm{C}-\mathrm{H}$ bending of alkane for methylene group and $1450 \mathrm{~cm}-1 \mathrm{C}-\mathrm{H}$ bending of alkane for methyl group. In conclusion, it is clear, peak near $2900 \mathrm{~cm}-1$ is due to alkane, near 1450 for $\mathrm{C}-\mathrm{H}$ bending of methyl group and $3200-3500 \mathrm{~cm}^{-1}$ because of O-H group [46].

\section{Conclusions}

In this study, tensile, water absorption and fire retardant properties of jute, E-glass and carbon Kevlar fabric reinforced polypropylene composites were investigated. The tensile strength as well as E-Modulus and water absorption of carbon Kevlar composite were exhibited better results than the jute and E-glass fabric reinforced composites. Different scenario has observed for elongation percentage at break. The capacity of fire retardant was noticed higher in jute fabric composite than jute and E-glass. Further investigation will be done to improve processing, to expand the application fields for jute E-glass and carbon Kevlar composites.

\section{REFERENCES}

[1] Islam, Tuhidul, Ruhul A. Khan, Mubarak A. Khan, MdArifur Rahman, Marcelo Fernandez-Lahore, Q. M. I. Huque, and R. Islam. "Physico-mechanical and degradation properties of gamma-irradiated biocomposites of jute fabric-reinforced poly (caprolactone)." Polymer-Plastics Technology and Engineering, Vol. 48, No. 11, pp.1198-1205, 2009

[2] Rahman, ANM Masudur, Shah Alimuzzaman, Ruhul A. Khan, and Jamal Hossen. "Evaluating the performance of gamma irradiated okra fiber reinforced polypropylene (PP) composites: comparative study with jute/PP." Fashion and Textiles, Vol. 5, No. 1, pp. 1-17, 2018.

[3] Jawaid, M., HPS Abdul Khalil, A. Abu Bakar, and P. Noorunnisa Khanam. "Chemical resistance, void content and tensile properties of oil palm/jute fibre reinforced polymer hybrid composites." Materials \& Design, Vol. 32, No. 2, pp.1014-1019, 2011.

[4] Karina, Myrtha, Holia Onggo, A H Dawam Abdullah, and
Anung Syampurwadi. "Effect of oil palm empty fruit bunch fiber on the physical and mechanical properties of fiber glass reinforced polyester resin." Journal of Biological Sciences, Vol. 8, No. 1, pp.101-106, 2008.

[5] Khalil, HPS Abdul, S. Hanida, C. W. Kang, and NA Nik Fuaad. "Agro-hybrid composite: the effects on mechanical and physical properties of oil palm fiber (EFB)/glass hybrid reinforced polyester composites." Journal of Reinforced Plastics and Composites, Vol. 26, No. 2, pp. 203-218, 2007.

[6] Khan, G M Arifuzzaman, Md Shaheruzzaman, M. H. Rahman, SM Abdur Razzaque, Md Sakinul Islam, and MdShamsul Alam. "Surface modification of okra bast fiber and its physico-chemical characteristics." Fibers and polymers, Vol. 10, No. 1, pp.65-70, 2009.

[7] Varada Rajulu, A., and R. Rama Devi. "Tensile properties of ridge gourd/phenolic composites and glass/ridge gourd/phenolic hybrid composites." Journal of Reinforced Plastics and composites, Vol. 26, No. 6, pp.629-638, 2007.

[8] Saba, N., M. T. Paridah, and M. Jawaid. "Mechanical properties of kenaffibre reinforced polymer composite: A review." Construction and Building materials, Vol. 76, pp.87-96, 2015

[9] Thiruchitrambalam, M., A. Athijayamani, S. Sathiyamurthy, and A. Syed Abu Thaheer. "A review on the natural fiber-reinforced polymer composites for the development of roselle fiber-reinforced polyester composite." Journal of Natural Fibers, Vol. 7, No. 4, pp.307-323, 2010.

[10] Gowda, T. Munikenche, A. C. B. Naidu, and Rajput Chhaya. "Some mechanical properties of untreated jute fabric-reinforced polyester composites." Composites Part A: applied science and manufacturing, Vol. 30, No. 3, pp.277-284, 1999.

[11] Gon, Debiprasad, Kousik Das, Palash Paul, and Subhankar Maity. "Jute composites as wood substitute." International Journal of Textile Science, Vol. 1, No. 6, pp.84-93, 2012.

[12] Júnior, José Humberto Santos Almeida, Heitor Luiz Ornaghi Júnior, Sandro Campos Amico, and Franco Dani Rico Amado. "Study of hybrid intralaminatecuraua/glass composites." Materials \& Design, Vol. 42, pp.111-117, 2012.

[13] Bullions, T. A., R. A. Gillespie, J. Price - O'Brien, and A. C. Loos. "The effect of maleic anhydride modified polypropylene on the mechanical properties of feather fiber, kraft pulp, polypropylene composites." Journal of applied polymer science, Vol. 92, No. 6, pp.3771-3783, 2004.

[14] Joseph, P. V., Kuruvilla Joseph, and Sabu Thomas. "Short sisal fiber reinforced polypropylene composites: the role of interface modification on ultimate properties." Composite Interfaces, Vol. 9, No. 2, pp.171-205, 2002.

[15] Mohanty, A. K., M. and Misra, and GiHinrichsen. "Biofibres, biodegradable polymers and biocomposites: An overview." Macromolecular materials and Engineering, Vol. 276, No. 1, pp.1-24, 2000.

[16] Zaman, Haydar U., Ruhul A. Khan, Mubarak A. Khan, and Md Dalour Hossen Beg. "Physico-mechanical and degradation properties of biodegradable photografted coir fiber with acrylic monomers." Polymer bulletin, Vol. 70, No. 8, pp.2277-2290, 2013. 
[17] Zaman, Haydar U., Mubarak A. Khan, Ruhul A. Khan, M. Z. I. Mollah, Shamim Pervin, and M. D. Al-Mamun. "A comparative study between gamma and UV radiation of jute fabrics/polypropylene composites: effect of starch." Journal of reinforced plastics and composites, Vol. 29, No. 13, pp.1930-1939, 2010

[18] Reddy, M. Indra, M. Anil Kumar, and Ch Rama Bhadri Raju. "Tensile and flexural properties of jute, pineapple leaf and glass fiber reinforced polymer matrix hybrid composites." Materials Today: Proceedings, Vol. 5, No. 1, pp.458-462, 2018.

[19] Haydaruzzaman, A. H. Khan, M. A. Hossain, Mubarak A. Khan, Ruhul A. Khan, and M. A. Hakim. "Effect of ultraviolet radiation on the mechanical and dielectric properties of Hessian cloth/PP composites with starch." Polymer-Plastics Technology and Engineering, Vol. 49, No. 8, pp.757-765, 2010.

[20] Khan, Mubarak A., K. M. Idriss Ali, G. Hinrichsen, C. Kopp, and S. Kropke. "Study on physical and mechanical properties of biopol-jute composite." Polymer-Plastics Technology and Engineering, Vol. 38, No. 1, pp.99-112, 1999.

[21] Ahmed, K. Sabeel, and S. Vijayarangan. "Experimental characterization of woven jute - fabric - reinforced isothalic polyester composites. "Journal of applied polymer science, Vol.104, No. 4, pp.2650-2662, 2007.

[22] Prasad, B. Durga, G. Kiran Reddy, and A. Anusha Yadav. "Mechanical Properties of Composite Material Reinforced by Jute and E-Glass Fibers." International Journal of Emerging Engineering Research and Technology, Vol. 2, No. 5, pp.135-138, 2014.

[23] Khan, Jahangir A., Mubarak A. Khan, Rabiul Islam, and Abdul Gafur. "Mechanical, thermal and interfacial properties of jute fabric-reinforced polypropylene composites: effect of potassium dichromate." Materials Sciences and Applications, Vol.1, No. 6, pp.350-357, 2010.

[24] Elbadry, Elsayed A., Mohamed S. Aly-Hassan, and Hiroyuki Hamada. "Mechanical properties of natural jute fabric/jute mat fiber reinforced polymer matrix hybrid composites." Advances in Mechanical Engineering, Vol. 4, pp. 1-12, 2012.

[25] Saha, A. K., S. Das, D. Bhatta, and B. C. Mitra. "Study of jute fiber reinforced polyester composites by dynamic mechanical analysis." Journal of applied polymer science, Vol. 71, No. 9, pp.1505-1513, 1999.

[26] Miah, Mohammad Julhash, Mubarak A. Khan, and Ruhul A. Khan. "Fabrication and characterization of jute fiber reinforced low density polyethylene based composites: effects of chemical treatment." Journal of Scientific Research, Vol. 3, No. 2, pp.249-259, 2011.

[27] Gassan, Jochen, and Andrzej K. Bledzki. "Possibilities for improving the mechanical properties of jute/epoxy composites by alkali treatment of fibres." Composites Science and Technology, Vol. 59, No. 9, pp. 1303-1309, 1999.

[28] Abdullah-Al-Kafi, M. Z. Abedin, M. D. H. Beg, K. L. Pickering, and Mubarak A. Khan. "Study on the mechanical properties of jute/glass fiber-reinforced unsaturated polyester hybrid composites: Effect of surface modification by ultraviolet radiation." Journal of Reinforced Plastics and Composites, Vol. 25, No. 6, pp. 575-588, 2006.

[29] Sathishkumar, T. P., S. Satheeshkumar, and J. Naveen. "Glass fiber-reinforced polymer composites-a review." Journal of Reinforced Plastics and Composites, Vol. 33, No. 13, pp.1258-1275, 2014.

[30] Aramide, F. O., P. O. Atanda, and O. O. Olorunniwo. "Mechanical properties of a polyester fibre glass composite." International Journal of Composite Materials, Vol. 2, No. 6, pp.147-151, 2012.

[31] López, F. A., M. I. Martín, F. J. Alguacil, J. Ma Rincón, T. A. Centeno, and M. Romero. "Thermolysis of fibreglass polyester composite and reutilisation of the glass fibre residue to obtain a glass-ceramic material." Journal of Analytical and Applied Pyrolysis, Vol. 93, pp.104-112, 2012.

[32] Erden, S., K. Sever, Y. Seki, and M. Sarikanat. "Enhancement of the mechanical properties of glass/polyester composites via matrix modification glass/polyester composite siloxane matrix modification." Fibers and Polymers, Vol. 11, No. 5, pp.732-737, 2010.

[33] Ramzan, Engr, and Engr Ehsan. "Effect of various forms of glass fiber reinforcements on tensile properties of polyester matrix composite." Fac. Eng. Technol, Vol. 16, pp.33-39, 2009.

[34] Alam, Shahzad, Farzana Habib, Muhammad Irfan, Waqas Iqbal, and Khuram Khalid. "Effect of orientation of glass fiber on mechanical properties of GRP composites." Journal of the Chemical Society of Pakistan, Vol. 32, No. 3, pp.265-269, 2010.

[35] Gupta, Nikhil, Balraj Singh Brar, and Eyassu Woldesenbet. "Effect of filler addition on the compressive and impact properties of glass fibre reinforced epoxy." Bulletin of Materials Science, Vol. 24, No. 2, pp.219-223, 2001.

[36] Faizal, Mohd Aidy, Yeo Kiam Beng, and Mohd Noh Dalimin. "Tensile property of hand lay-up plain-weave woven e-glass/polyester composite: Curing pressure and Ply arrangement effect." Borneo Sci, Vol. 19, pp.27-34, 2006.

[37] Avci, A., H. Arikan, and A. Akdemir. "Fracture behavior of glass fiber reinforced polymer composite." Cement and Concrete Research, Vol. 34, No. 3, pp. 429-434, 2004.

[38] Ellyin, Fernand, and Rachel Maser. "Environmental effects on the mechanical properties of glass-fiber epoxy composite tubular specimens." Composites Science and Technology, Vol. 64, No. 12, pp.1863-1874, 2004.

[39] Budai, Zoltán, Zsolt Sulyok, and Viktória Vargha. "Glass-fibre reinforced composite materials based on unsaturated polyester resins." Journal of thermal analysis and calorimetry, Vol.109, No. 3, pp.1533-1544, 2011.

[40] Agarwal, Bhagwan D., Lawrence J. Broutman, and K. Chandrashekhara. "Analysis and performance of fiber composites”, John Wiley \& Sons, USA, 2017.

[41] Matthews, Frank L., and Rees D. Rawlings. "Composite materials: engineering and science", CRC press, USA, 1999.

[42] Mallick, Pankar K. "Fiber-reinforced composites: materials, 
manufacturing, and design", CRC press, USA, 2007.

[43] Pregoretti, A., M. Traina, and A. R. Bunsell. "Handbook of Tensile Properties of Textile and Technical Fibers." Woodhead Publishing, UK, 2009.

[44] Davidson, Jacob D. "Multiscale modeling and simulation of crosslinked polymers.", PhD Dissertation, University of Michigan, USA, 2014.

[45] Repon, R., K. Z. M. A. Motaleb, M. Tauhidul Islam, R. Al Mamun, and M. R. Mithu. "Tensile and water absorption properties of jute and pineapple fabric reinforced polyester composite." International Journal of Composite Materials, Vol. 7, No.2, pp. 72-76, 2017.

[46] https://www.sigmaaldrich.com/technical-documents/article s/biology/ir-spectrum-table.html 